\title{
Quantitative differences between variants of A spermatogonia in man
}

\author{
R. Paniagua*, M. Nistal†, P. Amat $\ddagger$, M. C. Rodríguez*, and J. R. Alonso* \\ * Department of Cytology and Histology, Faculty of Biology, University of Salamanca, E-37008 \\ Salamanca; $\nmid$ Department of Morphology, School of Medicine, Autonomous University of Madrid, \\ E-28029 Madrid; and $\ddagger$ Department of Electron Microscopy, University Clinical Hospital, E-37007 \\ Salamanca, Spain
}

\begin{abstract}
Summary. The area of cytoplasm, nucleus, nucleolus and mitochondria, as well as the elongation and irregular outline of the nucleus were determined, on electron micrographs by using an image analyser, for Ap (pale), Ad (dark with intranuclear vacuole), Ad-like (dark without intranuclear vacuole), Ac (cloudy) and Al (long) human spermatogonia. Ap and Ac spermatogonia had a larger nucleus, larger nucleolus, and more cytoplasm than did Ad, Ad-like, and Al spermatogonia. In addition, the nuclei of Ap and Ac spermatogonia were more spherical and had a more distinct outline.
\end{abstract}

\section{Introduction}

In 1963 Clermont distinguished two variants (Ap and Ad) of A spermatogonia in the human testis on the basis of the staining affinity of the nuclei examined by light microscopy. Rowley, Berlin \& Heller (1971) confirmed this distinction by electron microscopy. Although these authors suggested that, in addition to the staining affinity of the nucleus, Ap and Ad variants show several morphological qualitative differences, these are not in keeping with those reported later by Hadziselimovic (1977), and several other ultrastructural studies have not corroborated such differences (Schulze, 1978a, b, 1979; Holstein \& Roosen-Runge, 1981; Nistal \& Paniagua, 1984). Moreover, about 30\% of spermatogonia seem to be difficult to classify, and new additional variants of A spermatogonia, such as the A 'long' (Al) (Rowley et al., 1971) and the A 'cloudy' (Ac) (Schulze, 1978a; Holstein \& Roosen-Runge, 1981), have been proposed. In addition, variations in the cell size of Ap and Ad spermatogonia have been reported in air-dried cell preparations of human testis (Curtis, 1985) as well as in human seminiferous tubules mounted in toto (Chowdhury \& Steinberger, 1977).

The aim of this report is to analyse possible quantitative differences between the previously reported variants of $\mathrm{A}$ spermatogonia in an attempt to provide additional information on the occurrence of two or more A spermatogonial populations in the human testis and their significance.

\section{Materials and Methods}

Testicular biopsies were obtained about $2 \mathrm{~h}$ after death from both testes of 25 adult men ( $27-42$ years of age) who died from traffic accidents (19 men) or other accidents (6 men), and had not suffered from testicular, endocrine or related pathological conditions. Testicular specimens were fixed in $3 \%$ cacodylate-buffered glutaraldehyde, postfixed in $1 \%$ veronal-buffered osmium tetroxide, and embedded in araldite. Semi-thin sections were stained with toluidine blue. Ultrathin sections were double stained with uranyl acetate and lead citrate and examined with a Philips-300 electron microscope. 


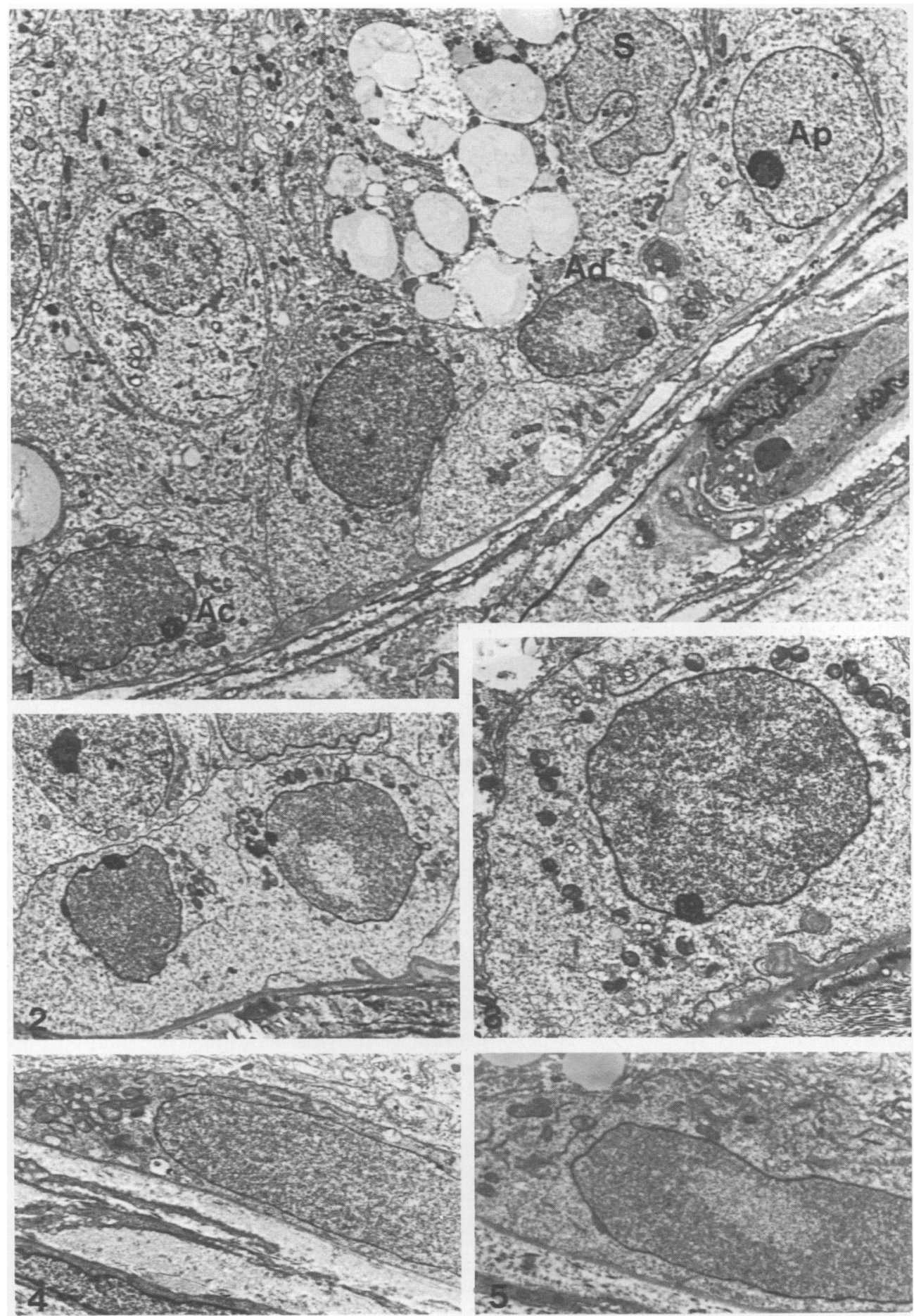


For the quantitative study, 15 cross-sectioned seminiferous tubules from each testis were examined by electron microscopy. From each tubule 3 cells corresponding to each of the 5 variants of A spermatogonia were serially sectioned and photographed at a final magnification of $\times 10000$. This amounts to a total of 45 cells from each different type per testis ( 90 per man). For each cell the section showing maximum nuclear diameter was chosen. The A spermatogonium variants selected were: Ap (pale) with nuclei lighter than those of Sertoli cells (Fig. 1); Ad (dark) with nuclei darker than those of Sertoli cells and intranuclear chromatin rarefaction zones (vacuoles (Figs 1 \& 2); Ad-like with nuclei darker than those of Sertoli cells but without intranuclear vacuoles (Fig. 2); Ac (cloudy) with intermingled light and dark chromatin areas (Fig. 3); and Al (long) with nuclei elongated parallel with the basal lamina (Fig. 4). Only cells that were easy to classify within these variants were chosen. Doubtful spermatogonia (about $5 \%$ ) suggesting intermediate stages between the A spermatogonium variants selected, such as elongated dark spermatogonia with intranuclear vacuoles (Fig. 5), were rejected because they did not form a homogeneous population. The area occupied by the cytoplasm, nucleus, nucleoli and mitochondria, as well as the nuclear perimeter and maximum and minimum nuclear diameters were measured with a semi-automatic image analyser (Kontron, Zeiss, Oberkochen, FRG). Repeated measurements showed 1-2\% error. For each parameter, the average values per each man were calculated. From these values, the mean and standard error of the mean were obtained. The significance of differences between means was evaluated by Student's $t$ test.

\section{Results}

Qualitative ultrastructural differences other than the chromatin pattern were not observed between the different A spermatogonium variants. Nucleoli attached to the nuclear membrane with both compact and trabecular portions, intranuclear areas of coarse granules, nuclear 'stripes' and 'blebs', cytoplasmic granulo-fibrillar masses similar to nuclear chromatin ('nuages'), Lubarsch crystals, glycogen granules (sometimes in vacuoles), paired or grouped mitochondria in contact or not with the nuclear membrane and joined by intermitochondrial bars, small Golgi complexes, some endoplasmic reticulum cisternae, and moderate amounts of ribosomes were observed in all the A spermatogonium variants.

The results of the quantitative study are shown in Table 1. For each characteristic measured, the differences between men were similar to those found between the different cells evaluated within each man. Ap and Ac spermatogonia differed from Ad, Ad-like and Al spermatogonia in the larger size of the nucleus and cytoplasm (1.3-1.4 times larger at sectioning), as well as in the much better

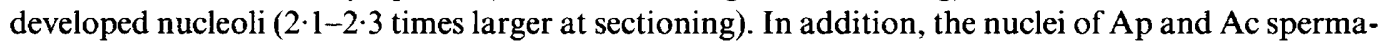
togonia were rounder and more regular in outline than those of Ad, Ad-like and Al spermatogonia.

Fig. 1. Part of a seminiferous tubule showing different variants of A spermatogonia including pale (Ap), dark with an intranuclear vacuole (Ad), and cloudy (Ac) spermatogonia. S: Sertoli cell. $\times 2900$.

Fig. 2. Binucleate spermatogonium showing two nuclei characteristic of Ad spermatogonia, one of them without an intranuclear vacuole. $\times 2900$.

Fig. 3. Higher magnification of an Ac (cloudy) spermatogonium showing the irregular stain of the nucleus with intermingled light and dark areas. $\times 4700$.

Fig. 4. Al (long) spermatogonium showing the elongated nucleus lying parallel to the basal lamina. $\times 3800$.

Fig. 5. Intermediate spermatogonium between $\mathrm{Al}$ and $\mathrm{Ad} . \times 4600$. 
Table 1. Quantitative differences between variants of A spermatogonia

\begin{tabular}{lccccc}
\hline & $\begin{array}{c}\text { Ap } \\
\text { (pale) }\end{array}$ & $\begin{array}{c}\text { Ac } \\
\text { (cloudy) }\end{array}$ & $\begin{array}{c}\text { Ad } \\
\text { (with } \\
\text { vacuole) }\end{array}$ & $\begin{array}{c}\text { Ad-like } \\
\text { (without } \\
\text { vacuole) }\end{array}$ & $\begin{array}{c}\mathrm{Al} \\
\text { (long) }\end{array}$ \\
\hline Area of cell $\left(\mu \mathrm{m}^{2}\right)$ & $141 \cdot 8 \pm 5 \cdot 7^{\mathrm{a}}$ & $150 \cdot 7 \pm 12^{\mathrm{a}, \mathrm{c}}$ & $100 \cdot 3 \pm 4 \cdot 6^{\mathrm{b}}$ & $99 \cdot 4 \pm 7 \cdot 8^{\mathrm{b}}$ & $109 \cdot 7 \pm 8 \cdot 9^{\mathrm{b}}$ \\
Area of nucleus $\left(\mu \mathrm{m}^{2}\right)$ & $49 \cdot 3 \pm 2 \cdot 7^{\mathrm{a}}$ & $51 \cdot 3 \pm 4 \cdot 0^{\mathrm{a}, \mathrm{c}}$ & $37 \cdot 2 \pm 2 \cdot 1^{\mathrm{b}}$ & $35 \cdot 5 \pm 3 \cdot 2^{\mathrm{b}}$ & $39 \cdot 7 \pm 3 \cdot 9^{\mathrm{b}}$ \\
Area of nucleolus $\left(\mu \mathrm{m}^{2}\right)$ & $1 \cdot 24 \pm 0 \cdot 2^{\mathrm{a}}$ & $1 \cdot 37 \pm 0 \cdot 2^{\mathrm{a}, \mathrm{c}}$ & $0 \cdot 52 \pm 0 \cdot 1^{\mathrm{b}}$ & $0 \cdot 49 \pm 0 \cdot 2^{\mathrm{b}}$ & $0 \cdot 57 \pm 0 \cdot 2^{\mathrm{b}}$ \\
Area of mitochondria $\left(\mu \mathrm{m}^{2}\right)$ & $3 \cdot 13 \pm 0 \cdot 2^{\mathrm{a}}$ & $3 \cdot 21 \pm 0.4^{\mathrm{a}}$ & $2 \cdot 91 \pm 0 \cdot 2^{\mathrm{a}}$ & $2 \cdot 98 \pm 0 \cdot 3^{\mathrm{a}}$ & $3 \cdot 24 \pm 0 \cdot 4^{\mathrm{a}}$ \\
Nuclear elongation* & $1 \cdot 18 \pm 0 \cdot 2^{\mathrm{a}}$ & $1 \cdot 15 \pm 0 \cdot 04^{\mathrm{a}, \mathrm{c}}$ & $1 \cdot 44 \pm 0 \cdot 03^{\mathrm{b}}$ & $1 \cdot 51 \pm 0 \cdot 03^{\mathrm{b}}$ & $1 \cdot 86 \pm 0 \cdot 07^{\mathrm{d}}$ \\
Irregular outline of the nucleus $\dagger$ & $1 \cdot 10 \pm 0 \cdot 01^{\mathrm{a}}$ & $1 \cdot 14 \pm 0 \cdot 03^{\mathrm{a}, \mathrm{c}}$ & $1 \cdot 28 \pm 0 \cdot 01^{\mathrm{b}}$ & $1 \cdot 25 \pm 0 \cdot 02^{\mathrm{b}}$ & $1 \cdot 27 \pm 0 \cdot 04^{\mathrm{b}}$ \\
\hline
\end{tabular}

Values are expressed as mean \pm s.e.m. Values with different superscript letters are significantly different, $P<0 \cdot 05$.

* Maximum nuclear diameter/minimum nuclear diameter.

$\uparrow$ Nuclear perimeter $/ 4 \pi$ nuclear area.

Al spermatogonia differed from Ad and Ad-like spermatogonia only in the greater elongation of the nucleus. No significant differences either between Ad and Ad-like spermatogonia or between Ap and Ac spermatogonia were found.

The numbers of Ap spermatogonia were lower in stages III-V of the cycle of the seminiferous epithelium than in the other stages. The number of Ac spermatogonia were higher in stage IV. No other relationships between A spermatogonium variants and the stages of the cycle were found.

\section{Discussion}

This is the first report on quantitative differences between different variants of A spermatogonia in man. The results suggest that Ap and Ad spermatogonia are two distinct cell populations. The Ap spermatogonia are larger cells showing more spherical nuclei with a more distinct outline and better developed nucleoli than the Ad spermatogonia. The occurrence of an intranuclear vacuole does not seem to be a prerequisite for Ad spermatogonia, since no quantitative differences between Ad and Ad-like spermatogonia were found. The Al spermatogonium seems to be a subvariant of Ad spermatogonium since the types differ only in the more elongated nucleus of $\mathrm{Al}$ spermatogonia. Since Ac spermatogonia did not differ quantitatively from Ap spermatogonia, they may be considered as a subvariant of the latter. The observation of higher standard errors in $\mathrm{Ac}, \mathrm{Ad}$ and $\mathrm{Al}$ spermatogonia than in Ap and Ad spermatogonia suggests that the subvariants are less homogeneously configured cell types and probably represent transformation from the Ap and Ad cell types during the cell cycle.

The significance of these findings may be considered on the basis of previously reported observations. Clermont (1966) postulated that Ad spermatogonia were the stem cells that give rise to Ap spermatogonia. Later studies added new information which has permitted other hypotheses. Ap spermatogonia persist while Ad spermatogonia decrease drastically in number or even disappear after radio- and chemotherapy (Schulze, 1979) as well as after treatment with the antiandrogen cyproterone acetate (Schulze, 1978a). Spermatocytes were present in the testes lacking in Ad spermatogonia and the recovery of spermatogenesis possibly takes place from the surviving Ap spermatogonia. It may be inferred from these observations that the occurrence of Ad spermatogonia is not a prerequisite for the formation of spermatocytes. Likewise, Holstein \& Wartenberg (1970) and Steinberger (1970) reported an A spermatogonial population consisting of only Ap spermatogonia in various patients with oligozoospermia and suggested that Ad spermatogonia are present only in cases with intact spermatogenesis. These findings led Schulze (1978a, b) to propose that Ap and Ad spermatogonia are not different generations but two distinct coexisting populations of cells, both of which may give rise to spermatozoa, and that certain forms of oligozoospermia may 
result from the elimination of the noxious-sensitive Ad spermatogonia. Studies of the $\left[{ }^{3} \mathrm{H}\right]$ thymidine labelling patterns of spermatogonia indicated that Ad spermatogonia may take part in the cycle of the seminiferous epithelium, and that $\mathrm{Ap}$ and Ad spermatogonia are unlabelled, suggesting that these cells are at the $G_{1}$ phase, whereas spermatogonia which are not well classified within Ap or Ad variants do incorporate $\left[{ }^{3} \mathrm{H}\right]$ thymidine Schulze, 1978a).

The present findings are in keeping with these hypotheses. Ap and Ad spermatogonia would be the two distinct $A$ spermatogonium populations at the $G_{1}$ phase. When DNA replication takes place in Ap spermatogonia these would develop into Ac spermatogonia. The occurrence of Ac spermatogonia and Ap spermatogonia in testes lacking Ad spermatogonia (Schulze, 1978a, 1979) also suggests this relationship.

This work was supported by a grant from the 'Comisión Asesora de Investigación Científica y Técnica', Madrid, Spain.

\section{References}

Chowdhury, A.K. \& Steinberger, E. (1977) In vitro ${ }^{3} \mathrm{H}$-thymidine labeling pattern and topographic distribution of spermatogonia in human seminiferous tubules. In The Testis in Normal and Infertile Men, pp. 69-83. Eds P. Troen \& H. R. Nankin. Raven Press, New York.

Clermont, Y. (1963) The cycle of the seminiferous epithelium in man. Am. J. Anat. 112, 35-51.

Clermont, Y. (1966) Renewal of spermatogonia in man. Am. J. Anat. 118, 509-524.

Curtis, D. (1985) Analysis of cell types identifiable in air-dried cell preparations of human testis. Cell Tissue Kinetics 18, 543-550.

Hadziselimovic, F. (1977) Cryptorchidism. Ultrastructure of normal and cryptorchid testis development. $A d v$. Anat. Embryol. Cell Biol. 53, fasc. 3, 1-72.

Holstein, A.F. \& Roosen-Runge, E.C. (1981) Atlas of Human Spermatogenesis. Grosse-Verlag, Berlin.

Holstein, A.F. \& Wartenberg, H. (1970) On the cytomorphology of human spermatogenesis. In Morphological Aspects of Andrology, pp. 8-12. Eds A. F. Holstein \& F. Horstmann. Grosse-Verlag, Berlin.
Nistal, M. \& Paniagua, R. (1984) Adult testis. In Testicular and Epididymal Pathology, pp. 26-51. Eds M. Nistal \& R. Paniagua. Thieme-Stratton, New York.

Rowley, M.J., Berlin, J.D. \& Heller, C.G. (1971) The ultrastructure of four types of human spermatogonia. Z. Zellforsch. mikrosk. Anat. 112, 139-157.

Schulze, W. (1978a) Licht- und elektronenmikroskopische Studien an der A-Spermatogonien von Männern mit intakter Spermatogenese und bei Patienten nach Behandlung mit Antiandrogenen. Andrologia 10, $307-320$.

Schulze, W. (1978b) Zum Problem der morphologischen Charakterisierung von Spermatogonientypen beim Erwachsenen. Verh. anat. Ges., Jena 72, 539-540.

Schulze, C. (1979) Morphological characteristics of the spermatogonial stem cells in man. Cell Tissue Res. 198, 191-199.

Steinberger, E. (1970) Comment on presentation of Y. Clermont. In The Human Testis, p. 60. Eds E. Rosenberg \& C. A. Paulsen. Plenum Press, New York.

Received 15 January 1986 